E-JURNAL EKONOMI DAN BISNIS UNIVERSITAS UDAYANA
Available online at https://ojs.unud.ac.id/index.php/EEB/index
Vol. 10 No. 01, January 2021, pages: 11-22
e-ISSN: 2337-3067

\title{
EVALUASI TINGKAT PENERIMAAN E-MONEY DI KALANGAN MAHASISWA YOGYAKARTA MENGGUNAKAN MODIFIKASI UTAUT2
}

\author{
Irfan Evan ${ }^{1}$ Wing Wahyu Winarno ${ }^{2}$ Hanson Prihantoro Putro ${ }^{3}$
}

Article history:

Submitted: 17 Oktober 2020

Revised: 2 Desember 2020

Accepted: 6 Desember 2020

\section{Keywords:}

E-Money;

UTAUT2;

Multiple Linear Regression;

Kata Kunci:

E-Money;

Regresi Linear Berganda; UTAUT2;

\section{Koresponding:}

Fakultas Teknik Industri, Universitas Islam Indonesia, Yogyakarta, Indonesia Email:17917211@student.uii .ac.id
Abstract

Based on data from Bank Indonesia, the volume and value of electronic money transactions has grown significantly in the last 10 years. But in reality, the number of users is still small when compared to debit cards. Many factors cause people to be reluctant to use e-money as a method of electronic transactions. Therefore, this study will evaluate the acceptance rate of electronic money among students and the factors that affect its acceptance. This study uses UTAUT2 which can add Trust, Perceived Risk and Perceived Security variables. Data was collected through distributing questionnaires online using google forms to 180 users. The data analysis method in this study used multiple linear regression and used SPSS software. The result, the level of acceptance of e-money among students is in a good category. It is known, Behavior Intention positively by Perceived Security, Price Value, Habit, Performance Expectancy, Trust, Facilitating Condition, Hedonic Motivation and negatively by Perceived Risk but not by Effort Expectancy and Social Influence.

\section{Abstrak}

Jumlah penggunanya masih sedikit jika dibandingkan kartu debit. Banyak faktor yang menyebabkan masyarakat masih enggan untuk menggunakan e-money, di antaranya seperti masyarakat masih khawatir memberikan informasi pribadi, jaringan infrastruktur yang belum menyeluruh ke semua pelosok negeri, dan masyarakat Indonesia secara budaya lebih nyaman memegang dan bertransaksi secara tunai. Oleh karena itu, penelitian ini bertujuan untuk mengevaluasi tingkat penerimaan $e$ money di kalangan mahasiswa dan faktor-faktor apa aja yang mempengaruhi penerimaannya. Penelitian ini menggunakan UTAUT2 yang dimodifikasi dengan menambahkan variabel Trust, Perceived Risk dan Perceived Security. Data dikumpulkan melalui penyebaran kuesioner secara online menggunakan google form ke 180 pengguna. Metode analisis data dalam penelitian ini menggunakan regresi linear berganda dan menggunakan software SPSS. Hasilnya, tingkat penerimaan e-money di kalangan mahasiswa masuk dalam kategori baik. Diketahui, Behavior Intention secara positif dipengaruhi oleh Perceived Security, Price Value, Habit, Performance Expectancy, Trust, Facilitating Conditions, Hedonic Motivation dan secara negatif dipengaruhi oleh Perceived Risk namun tidak dipengaruhi oleh Effort Expectancy dan Social Influence.

Fakultas Akuntansi Sekolah Tinggi Ilmu Ekonomi YKPN, Yogyakarta ${ }^{2}$

Email: wing@stieykpn.ac.id

Fakultas Teknik Industri, Universitas Islam Indonesia ${ }^{3}$

Email: hanson@uii.ac.id 


\section{PENDAHULUAN}

E-money yang diluncurkan pada tahun 2007 di Indonesia mempunyai beragam kelebihan yang dimiliki sehingga mampu menggeser peran uang tunai sebagai alat pembayaran dalam melakukan transaksi. Transaksi menggunakan uang elektronik lebih akurat karena menggunakan komputer dan mesin sebagai alat. Selain itu penggunaan e-money berbasis server lebih simpel karena tidak diperlukan otorisasi seperti pin atau tanda tangan dan tidak perlu menjadi nasabah bank karena pembayarannya tidak ditarik dari rekening bank layaknya kartu kredit atau kartu debit.

Berdasarkan fakta di atas, dapat diketahui fenomena uang elektronik di Indonesia masih belum maksimal dimanfaatkan oleh masyarakat. Di sisi lain pemerintah bukan nya mendorong jumlah pengguna transaksi elektronik menggunakan uang elektronik seperti Gopay, Ovo, Dana, LinkAja dan sejenisnya agar terus meningkat melainkan mendorong penggunaan kartu debit dengan program satu orang memiliki satu kartu debit. Selain itu, banyak faktor yang menyebabkan masyarakat masih enggan untuk menggunakan e-money sebagai metode transaksi elektronik ini, diantaranya masyarakat masih khawatir tentang memberikan informasi pribadi termasuk nomor kartu identitas, nomor telepon, ID $e$-wallet, nomor rekening bank atau alamat email. Kemudian yang menjadi penghambat utama kebijakan transaksi elektronik ini yaitu, iklim atau ekosistem bisnis dan permasalahan klasik infrastruktur seperti internet yang belum menyeluruh ke seluruh pelosok negeri, tertinggalnya perkembangan transaksi elektronik di Indonesia juga dipengaruhi oleh masyarakat Indonesia yang secara budaya masih lebih nyaman memegang dan bertransaksi secara tunai (Indah, 2018)

Dengan tidak diperhatikannya layanan transaksi uang elektronik ini, maka dapat mengakibatkan tidak berkembangnya proses bisnis yang sudah direncanakan oleh pemerintah yaitu Cashless Society, permintaan uang kartal yang tinggi, serta tidak ditemukannya efisiensi dalam proses bisnis. Hal ini akan berujung kepada perekonomian Indonesia yang kurang bersaing dalam menghadapi persaingan bisnis secara global. Argumen ini didasari dengan kebijakan Bank Indonesia (2019) yaitu sistem pembayaran yang bertujuan untuk mendukung pertumbuhan ekonomi dengan cara meningkatkan kelancaran, keamanan, dan efisiensi transaksi. Kebijakan Bank Indonesia juga diarahkan untuk mengantisipasi berbagai tantangan, sehingga sistem pembayaran dapat terus menopang kesinambungan pertumbuhan ekonomi. Selain itu, transaksi menggunakan uang elektronik tidak hanya membantu negara mencapai stabilitas ekonomi, tetapi juga memiliki peluang untuk mengurangi kegiatan korupsi di Indonesia. Pertumbuhan penggunaan uang elektronik tidak terlepas dari peran pemasaran dalam mengenalkan produk tersebut kepada masyarakat luas terutama daerah yang baru memfasilitasi sistem pembayaran elektronik.

Penelitian Hsiao \& Tang (2014) telah melakukan penelitian dengan lima model penerimaan teknologi dan membuktikan bahwa model UTAUT adalah model yang terbaik pada konteks teknologi. Selain itu, tingkat efisiensi dari model UTAUT adalah presentase yang paling tinggi yaitu sebesar $70 \%$ dibandingkan dengan model penerimaan teknologi lainnya (Venkatesh, et al, 2003). Kemudian model UTAUT dikembangkan sebagai model terintegrasi yang komprehensif untuk lebih memahami penerimaan dan penggunaan konsumen terhadap teknologi atau sistem baru. Pengembangan model UTAUT dinamakan model UTAUT2 yang bertujuan untuk mengidentifkasi penggunaan dan penerimaan teknologi, baik untuk konsumen maupun umum dengan mengubah beberapa hubungan yang sudah ada pada konsep model UTAUT dan mengenalkan hubungan baru (Venkatesh, et al 2012).

Pada model UTAUT2 terdapat tujuh konstruk yang menjadi faktor penentu terhadap niat perilaku (behavior intention) dan penggunaan teknologi (use behavior) yang terdiri dari performance expectancy, effort expectancy, social influence, facilitating condition, hedonic motivation, price value, dan habit. Akan tetapi, pada penelitian ini menghilangkan variabel perilaku pengguna (use behavior) karena niat perilaku (behavior intention) juga merupakan prediktor terkuat dari use behavior (Sanctis,

Evaluasi Tingkat Penerimaan E-Money Di Kalangan Mahasiswa Yogyakarta Menggunakan Modifikasi Utaut2 Irfan Evan, Dkk 
1983; Hill, et al 1987) dan telah dibuktikan oleh penelitian-penelitian terdahulu dalam konteks transaksi elektronik (Martins, et al 2014; Bhatiasevi, 2015; Alalwan, et al, 2017; Limantara et al 2018). Penelitian ini juga menghapus variabel moderator yang ada pada UTAUT2 yaitu age, gender, experience. Hal itu dikarenakan, fokus dari penelitian ini adalah untuk mengevaluasi tingkat penerimaan e-money di kalangan mahasiswa tanpa melihat age, gender dan experience. Disamping itu, Alharbi dkk (2017) juga menjelaskan bahwa variabel moderasi tersebut merupakan variabel-variabel yang digunakan untuk penelitian adopsi awal. Ini tentu berbeda konteksnya dengan penelitian ini karena penelitian ini respondennya merupakan mahasiswa yang sudah menjadi pengguna produk $e$ money, bukan calon pengguna.

Dalam konteks e-money di Indonesia, sudah ada yang melakukan penelitian sebelumnya seperti penelitian Widodo dkk (2019) mengidentifikasi faktor-faktor yang mempengaruhi adopsi $e$ wallet di Indonesia berdasarkan model UTAUT2 dengan penambahan risiko yang dirasakan dan faktor kepercayaan. Hasil penelitian menunjukkan bahwa risiko yang dirasakan tidak mempengaruhi niat untuk mengadopsi e-wallet. Hal ini bertentangan dengan hasil penelitian Alalwan (2018) yang mengatakan bahwa risiko yang dirasakan berpengaruh pada niat pelanggan untuk menggunakan internet banking karena faktor keuangan yang terlibat di dalamnya. Pengadopsi teknologi baru perlu memahami implikasi negatif dan positif dari penggunaannya, oleh karena itu persepsi risiko dianggap sebagai salah satu faktor penting dalam konteks transaksi elektronik (Slade, et al 2015; Park, Amendah, et al, 2019).

Penelitian Limantara (2018) menguji faktor-faktor yang mempengaruhi adopsi mobile payment di Indonesia. Penelitian ini menggunakan model UTAUT2 dengan menambahkan beberapa faktor seperti kepercayaan dan persepsi risiko. Hasil dari penelitian menunjukkan bahwa variabel kepercayaan tidak mempengaruhi niat pelanggan untuk menggunakan mobile payment. Hasil ini bertentangan dengan penelitian terdahulu (Al-Fahim, et al 2015; Chaouali, et al 2016; Alalwan, dkk, 2017) yang mengatakan bahwa kepercayaan dapat mempengaruhi niat perilaku untuk mengadopsi sistem pembayaran elektronik. Oleh karena itu, dalam penelitian ini akan menambahkan variabel kepercayaan (trust) karena sistem pembayaran elektronik memerlukan kepercayaan untuk komunikasi yang efektif dan pembayaran yang aman karena tidak seperti pertukaran yang dilakukan secara tradisional dimana lebih sedikit kepercayaan diperlukan, sesuai dengan pendapat (Salloum \& AlEmran, 2018) juga mengatakan bahwa kepercayaan penuh dari pelanggan terhadap sistem pembayaran elektronik adalah persyaratan yang paling utama.

Penelitian Widyanto dkk (2020) menganalisa faktor-faktor yang mempengaruhi niat untuk menggunakan aplikasi mobile payment dengan menggunakan model UTAUT2 dengan menambahkan beberapa faktor seperti kepercayaan dan persepsi keamanan. Penelitian ini menunjukkan bahwa persepsi keamanan tidak mempengaruhi niat untuk menggunakan aplikasi mobile payment. Hasil ini bertentangan dengan penelitian terdahulu (Pedersen, et al, 2015; Yang, et al, 2015) yang menyatakan bahwa selama aktivitas transaksi keuangan secara online, keamanan layanan merupakan pertimbangan utama bagi pengguna. Persepsi keamanan mengacu pada persepsi konsumen dengan kemungkinan menjadi korban kejahatan saat menggunakan teknologi (Rader, et al, 2015). Persepsi keamanan mempengaruhi niat untuk menggunakan transaksi elektronik (Shin, 2010; Junadi \& Sfenrianto, 2015; Cabanillasa, et al, 2018), dengan demikian relevan dalam penelitian ini bahwa persepsi keamanan dalam konteks konsumen akan mempengaruhi niat untuk menggunakan $e$-money.

Berdasarkan latar belakang di atas, maka peneliti tertarik melakukan penelitian dengan menggunakan teori UTAUT2 yang telah di modifikasi bersama faktor persepsi risiko, persepsi keamanan dan kepercayaan terhadap niat mahasiswa DIY untuk menggunakan e-money sebagai metode pembayaran elektronik sehari-hari. Penelitian ini juga menggunakan mahasiswa sebagai responden karena tingkat literasi dan iklusif keuangannya memiliki potensi besar sebagai penggerak perekonomian Indonesia, baik dari segi jumlah populasi, karakter dan tingkat literasi serta iklusif 
keuangan (Otoritas Jasa Keuangan, 2019). Harapan dengan adanya penelitian ini bisa sebagai bahan evaluasi pemerintah dan penyedia layanan e-money untuk memperbaiki kebijakan-kebijakan terhadap penyelenggaraan $e$-money sehingga dapat dimanfaatkan untuk meningkatkan niat perilaku adopsi uang elektronik bagi para pengguna, baik pengguna awal, pengguna yang telah lama menggunakan dan bahkan pengguna potensial yang belum menggunakan uang elektronik sebagai alat pembayaran.

Adapun hipotesis yang diajukan dalam penelitian ini untuk menjawab rumusan masalah, yaitu sebagai berikut: Hubungan antara Ekspektasi Kinerja dan Niat Perilaku Ekspektasi kinerja mengacu pada tingkat dimana seseorang mempercayai bahwa menggunakan sistem akan membawa manfaat bagi pengguna dalam kinerja tugas tertentu (Venkatesh, et al, 2012). Berdasarkan penjelasan di atas maka peneliti merumuskan hipotesis: H1: Ekspektasi kinerja memiliki pengaruh positif terhadap minat pengunaan e-money. Hubungan antara Ekspektasi Usaha dan Niat Perilaku. Ekspektasi usaha adalah tingkat kemudahan yang terkait dengan penggunaan teknologi yang dilakukan oleh konsumen. Berdasarkan penjelasan di atas maka peneliti merumuskan hipotesis: H2: Ekspektasi Usaha memiliki pengaruh positif terhadap minat pengunaan e-money. Hubungan antara Pengaruh Sosial dan Niat Perilaku. Pengaruh sosial mengacu pada tingkat di mana seorang individu melihat esensi orang lain dalam meyakini bahwa seseorang harus memanfaatkan teknologi baru. Berdasarkan uraian di atas maka peneliti merumuskan hipotesis: H3: Pengaruh sosial memiliki pengaruh positif terhadap minat pengunaan e-money. Hubungan antara Kondisi Fasilitas dan Niat Perilaku. Kondisi fasilitas mengacu pada sejauh mana seorang individu percaya bahwa ada infrastruktur teknis untuk membantu penggunaan sistem. Berdasarkan uraian di atas maka peneliti merumuskan hipotesis: H4: Kondisi fasilitas memiliki pengaruh positif terhadap minat pengunaan e-money. Hubungan antara Motivasi Hedonis dan Niat Perilaku. Motivasi hedonis didefinisikan sebagai kesenangan atau kesenangan yang terkait ketika menggunakan teknologi (Brown \& Venkatesh, 2005). Berdasarkan uraian di atas maka peneliti merumuskan hipotesis: H5: Motivasi hedonis memiliki pengaruh positif terhadap minat pengunaan e-money.

Hubungan antara Nilai Harga dan Niat Perilaku. Nilai harga adalah kondisi yang mengharuskan pelanggan ketika menggunakan teknologi harus peka apakah teknologi memberikan keuntungan dan manfaat lebih besar daripada biaya yang. Berdasarkan uraian di atas maka peneliti merumuskan hipotesis: H6: Nilai harga memiliki pengaruh positif terhadap minat pengunaan $e$-money. Hubungan antara Kebiasaan dan Niat Perilaku. Kebiasaan telah didefinisikan sejauh mana orang cenderung melakukan perilaku secara otomatis karena belajar. Berdasarkan uraian di atas maka peneliti merumuskan hipotesis: H7: Kebiasaan memiliki pengaruh positif terhadap minat pengunaan $e$ money. Hubungan antara Kepercayaan dan Niat Perilaku. Menurut Alzahrani \& Goodwin (2012), UTAUT2 kurangnya unsur kepercayaan. Signifikansi kepercayaan meningkatkan kesediaan pengguna untuk melakukan transaksi elektronik (Al-Fahim, et al, 2015; Chaouali, et al, 2016; Sinha \& Mukherjee, 2016; Alalwan, dkk, 2017) Berdasarkan uraian di atas maka peneliti merumuskan hipotesis: H8: Kepercayaan memiliki pengaruh positif terhadap minat pengunaan e-money. Hubungan antara Persepsi Risiko dan Niat Perilaku. Eiser (2002) berpendapat bahwa pengadopsi teknologi baru perlu memahami implikasi negatif dan positif dari penggunaannya, oleh karena itu risiko yang dirasakan dianggap salah satu faktor penting yang mempengaruhi perilaku konsumen. Berdasarkan uraian di atas maka peneliti merumuskan hipotesis: H9: Persepsi risiko memiliki pengaruh negatif terhadap minat pengunaan e-money. Hubungan antara Persepsi Keamanan dan Niat Perilaku. Perceived security (PS) mengacu pada persepsi keamanan terhadap risiko yang terkait dengan transaksi seluler, khususnya risiko kehilangan data rahasia yang pada gilirannya akan menyebabkan kerugian finansial, privacy (Ooi \& Tan, 2016). Berdasarkan uraian di atas maka peneliti merumuskan hipotesis: H10: Persepsi keamanan memiliki pengaruh positif terhadap minat pengunaan e-money. Berdasarkan hipotesis di atas, maka model penelitian yang digunakan dalam penelitian ini bisa dilihat pada Gambar 1. 


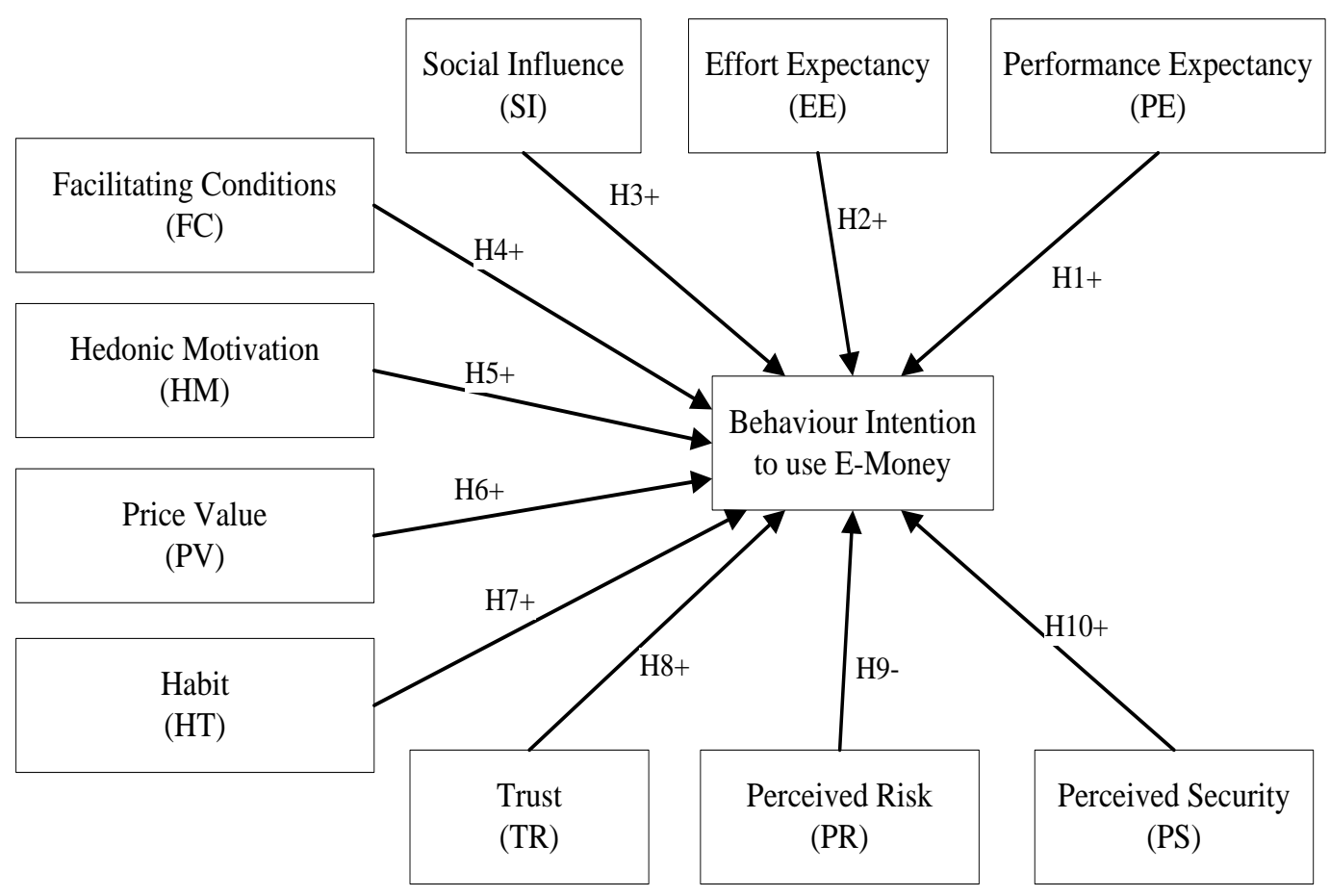

Gambar 1.

Model Penelitian

\section{METODE PENELITIAN}

Populasi adalah suatu wilayah pada umumnya yang terdiri atas objek atau subjek yang mempunyai kualitas dan karakteristik tertentu yang ditetapkan oleh peneliti untuk dipelajari dan kemudian ditarik kesimpulan (Sugiyono, 2010). Responden dalam penelitian ini yaitu mahasiswa DIY yang sudah menggunakan produk e-money sebagai metode pembayaran sehari-hari.

Populasi yang digunakan dalam penelitian ini yaitu mahasiswa DIY sebanyak 409.984 orang. Salah satu metode yang digunakan untuk menentukan jumlah minimal sampel adalah menggunakan rumus Slovin sebagai berikut:

$$
\mathrm{n}=\frac{\mathrm{N}}{1+\mathrm{N} \cdot \mathrm{e}^{\mathrm{2}}}
$$

Dimana :

$\mathrm{n}=$ ukuran sampel

$\mathrm{N}=$ ukuran populasi

$\mathrm{e}=$ taraf kesalahan $10 \%$

dapat diimplementasikan berdasarkan rumus slovin :

$$
\begin{aligned}
& \mathrm{n}=\frac{409.984}{1+(409.984)(0.1)^{2}} \text {. } \\
& \mathrm{n}=\frac{409.984}{1+4099,8}=99,9 \text { dibulatkan menjadi } 100 \text { orang }
\end{aligned}
$$


Berdasarkan perhitungan rumus, minimal jumlah sampel pada penelitian ini sebesar 100 orang. Teknik pengambilan sampel dalam penelitian ini menggunakan teknik non probability sampling. Teknik non probability sampling merupakan teknik pengambilan sampel yang tidak memberikan peluang yang sama untuk dipilih menjadi sampel (Kurniawan \& Puspitaningtyas, 2016). Sementara pemilihan respondennya menggunakan purposive sampling yang merupakan teknik pengambilan sampel berdasarkan pertimbangan tertentu dari anggota populasi. Kriteria untuk menjadi responden dalam penelitian ini yaitu mahasiswa DIY yang menggunakan produk e-money (Ovo, Gopay, Dana, LinkAja, dan sejenisnya) sebagai metode pembayaran elektronik.

Kuesioner yang digunakan menggunakan skala likert untuk mengukur sikap, pendapat dan persepsi seseorang atau kelompok orang tentang fenomena sosial (Sugiyono, 2010). Dalam penelitian ini menggunakan skala dari 1 sampai dengan 5 , dengan keterangan $1=$ sangat tidak setuju, $2=$ tidak setuju, $3=$ netral, $4=$ setuju dan $5=$ sangat setuju.

Data yang telah dikumpulkan untuk menunjang penelitian ini akan dianalisis menggunakan model regresi linear berganda dengan bantuan alat uji statistik yaitu software SPSS 25. Namun, data juga akan dianalisis menggunakan statistik deskriptif, uji validitas, reliabilitas dan uji asumsi klasik. Dimana, statistik deskriptif bertujuan untuk mengetahui distribusi data, uji validitas dan reliabilitas bertujuan untuk menguji kualitas data dalam penelitian ini sedangkan uji asumsi klasik digunakan untuk menguji kelayakan model regresi yang digunakan. Setelah diketahui bahwa model regresi layak, maka selanjutnya data dianalisis menggunakan uji koefisien determinasi (R2), uji signifikan parsial (Uji T), dan uji signifikan simultan (Uji F).

\section{HASIL DAN PEMBAHASAN}

Data diperoleh melalui metode survei dengan menggunakan kuesioner yang disebarkan hanya secara online melalui Google Form. Dari penyebaran kuesioner yang dilakukan pada tanggal 07 Mei 2020 - 10 Juni 2020, ternyata jumlah responden yang berkontribusi dalam pengisian kuesioner mencapai 180. Semua kuesioner yang kembali telah memenuhi syarat untuk dianalisis.

Untuk mengetahui distribusi jawaban responden dalam menjawab pertanyaan atau pernyataan dalam kuesioner perlu dilakukannya analisis deskriptif variabel yang bertujuan untuk mengetahui tingkat penerimaan e-money di kalangan mahasiswa. Variabel pada penelitian dinilai dengan melihat dari nilai rata-rata dan memberi arti nilai tersebut dengan membuat kriteria berdasarkan pada interval kelas rata-rata. Interval kelas yang digunakan berdasarkan pada rumus (Durianto, dkk 2001) :

$$
\text { Interval }=\frac{\text { Nilai Tertinggi-Nilai Terendah }}{\text { Banyaknya Kelas }} .
$$

Sehingga didapatkan hasil:

$$
\text { Interval }=\frac{5-1}{5}=0,8
$$

Berdasarkan hasil perhitungan, maka didapatkan interval kelas pada setiap skala yang digunakan dalam penelitian ini dan kategori tingkat penerimaannya seperti yang bisa dilihat pada Tabel 1. 
Tabel 1.

Kategori Tingkat Penerimaan

\begin{tabular}{cc} 
Interval Kelas & Kategori \\
\cline { 2 - 2 } $1,00 \leq x \leq 1,80$ & Sangat Buruk \\
$1,81 \leq x \leq 2,61$ & Buruk \\
$2,62 \leq x \leq 3,42$ & Cukup \\
$3,43 \leq x \leq 4,23$ & Baik \\
$4,24 \leq x \leq 5,00$ & Sangat Baik \\
\hline
\end{tabular}

Sumber: Data Primer (diolah), 2020

Tingkat penerimaan e-money di kalangan mahasiswa secara keseluruhan variabel yang digunakan dapat dilihat pada Tabel 2.

Tabel 2.

Tingkat Penerimaan Secara Keseluruhan

\begin{tabular}{|c|c|c|}
\hline Variabel & Rata-Rata & Kategori \\
\hline Performance Expectancy & 4,20 & Baik \\
\hline Effort Expectancy & 4,12 & Baik \\
\hline Facilitating Conditions & 4,06 & Baik \\
\hline Hedonic Motivation & 3,85 & Baik \\
\hline Price Value & 4,29 & Sangat Baik \\
\hline Habit & 3,45 & Baik \\
\hline Social Influence & 3,38 & Cukup \\
\hline Perceived Security & 3,73 & Baik \\
\hline Trust & 3,94 & Baik \\
\hline Perceived Risk & 3,39 & Cukup \\
\hline Behavior Itention & 3,68 & Baik \\
\hline Total & 3,82 & Baik \\
\hline
\end{tabular}

Sumber: Data Primer (diolah), 2020

Berdasarkan Tabel 2 dapat diketahui bahwa tingkat penerimaan e-money secara keseluruhan variabel yang digunakan memiliki nilai rata-rata 3,82. Nilai rata-rata tersebut menunjukkan bahwa tingkat penerimaan e-money di kalangan mahasiswa secara keseluruhan dalam kategori "Baik".

Pengujian normalitas akan dilakukan dengan metode grafik yaitu dengan melihat penyebaran data pada sumber diagonal grafik normal P-P Plot of Regression Standardized Residual. Menurut Ghozali (2011), model regresi dikatakan berdistribusi normal jika data ploting (titik-titik) yang menggambarkan data sesungguhnya mengikuti garis diagonal.

Berdasarkan Gambar 2, dapat dilihat bahwa titik-titik yang menyebar di sekitar garis diagonal dan penyebaran titik-titik data searah dengan garis diagonal. Hal ini menunjukkan bahwa model asumsi regresi memenuhi normalitas dan model regresi layak untuk menganalisis pengaruh variabelvariabel bebas terhadap variabel terikat. 


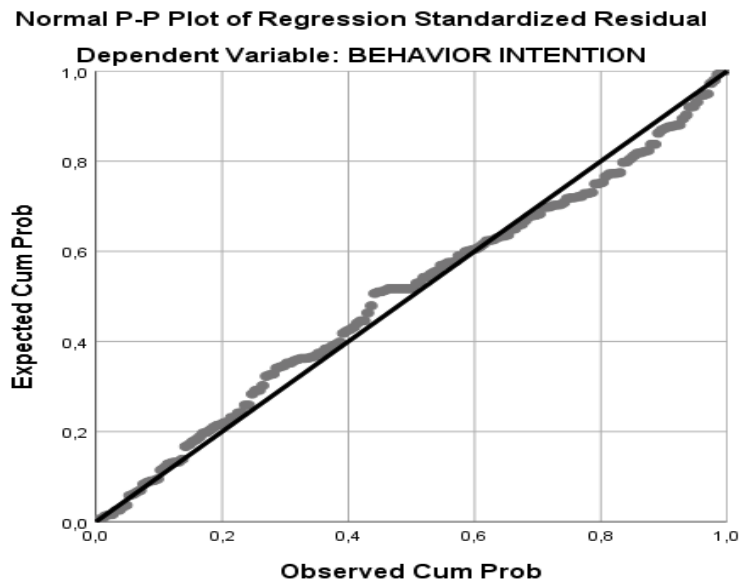

Sumber: Data Primer (diolah), 2020

Gambar 2.

Uji Normalitas Secara Grafik

Uji multikollinearitas pada penelitian ini digunakan untuk melihat ada atau tidaknya gejala multikollinearitas antar variabel bebas (independen). Jika nilai VIF tidak melebihi 10 maka dapat dikatakan bahwa lolos uji multikollinearitas (Ghozali, 2011).

Tabel 3.

Uji Multikolinearitas

\begin{tabular}{|c|c|c|}
\hline \multirow[t]{2}{*}{ Variabel } & \multicolumn{2}{|c|}{ Collinearity Statistics } \\
\hline & Tolerance & VIF \\
\hline Performance Expectancy & 0,405 & 2,467 \\
\hline Effort Expectancy & 0,296 & 3,381 \\
\hline Social Influence & 0,430 & 2,325 \\
\hline Facilitating Conditions & 0,429 & 2,329 \\
\hline Hedonic Motivation & 0,226 & 4,419 \\
\hline Habit & 0,291 & 3,431 \\
\hline Price Value & 0,283 & 3,528 \\
\hline Trust & 0,357 & 2,803 \\
\hline Perceived Risk & 0,805 & 1,243 \\
\hline Perceived Security & 0,494 & 2,024 \\
\hline
\end{tabular}

Sumber: Data Primer (diolah), 2020

Berdasarkan Tabel 3, hasil uji Variance Inflation Factor (VIF) pada hasil output SPSS 25 tabel coefficient masing-masing variabel independen memiliki VIF dengan nilai kesil dari 10 dan memiliki nilai Tolerance besar dari 0,10 , sehingga dapat disimpulkan bahwa tidak terjadi multikolinearitas.

Salah satu cara yang paling akurat untuk mendeteksi heteroskedastisitas adalah dengan menggunakan uji glejser. Uji glejser dilakukan dengan cara meregresikan variabel independen dengan nilai absolut residualnya (Ghozali, 2011). Dasar pengambilan keputusan uji glejser adalah jika nilai signifikansi (sig) antara variabel independen dengan absolut residual lebih besar dari 0,05 (5\%) maka tidak terjadi masalah heteroskedastisitas.

Evaluasi Tingkat Penerimaan E-Money Di Kalangan Mahasiswa Yogyakarta Menggunakan Modifikasi Utaut2 Irfan Evan, Dkk 
Tabel 4.

Uji Heteroskedastisitas

\begin{tabular}{lll}
\hline & Variabel & Residual \\
\hline Performance Expectancy & 0,768 \\
Effort Expectancy & 0,331 \\
Social Influence & 0,536 \\
Facilitating Conditions & 0,811 \\
Hedonic Motivation & 0,773 \\
Habit & 0,666 \\
Price Value & 0,828 \\
Trust & 0,784 \\
Perceived Risk & 0,586 \\
Perceived Security & 0,520 \\
\hline
\end{tabular}

Sumber: Data Primer (diolah),2020

Berdasarkan Tabel 4, hasil uji metode glejser pada hasil output SPSS 25 tabel coefficient masing-masing variabel independen memiliki residual dengan nilai besar dari 0,05 , sehingga dapat disimpulkan bahwa pada model regresi tidak terjadi heteroskedastisitas.

\section{Tabel 5.}

Uji R2

\begin{tabular}{cccc}
\hline Variabel & R Square & Adjusted $\boldsymbol{R}$ Square \\
\hline Behavior Intention & 0,715 & 0,698 & \\
\hline
\end{tabular}

Sumber: Data Primer (diolah), 2020

Pada Tabel 5 dapat dilihat bahwa nilai $R$-Square dari variabel Behavior Intention (BI) adalah sebesar 0.715 yang berarti bahwa variabel performance expectancy, effort expectancy, social influence, facilitating conditions, hedonic motivation, habit, price value, trust, perceived risk, dan perceived security mempengaruhi variabel Behavior Intention sebesar 71,5\% dan sisanya sebesar $28,5 \%$ dipengaruhi oleh variabel lain.

Tabel 6.

Uji F

\begin{tabular}{llll}
\hline Model & Df & F & Sig. \\
\hline Regression & 10 & 42,371 &, $000^{\mathrm{b}}$ \\
\hline Sumber: Data Primer (diolah) 2020 & & &
\end{tabular}

Berdasarkan Tabel 6, hasil uji $\mathrm{F}$ menunjukkan nilai signifikan kurang dari 0,05 dan nilai $\mathrm{F}$ hitung $(42,371)>\mathrm{F}$ tabel $(1,89)$ sehingga dapat disimpulkan bahwa model dapat digunakan untuk menggambarkan variabel performance expectancy, effort expectancy, social influence, facilitating conditions, hedonic motivation, habit, price value, trust, perceived risk, perceived security terhadap variabel behavior intention to use e-money. 


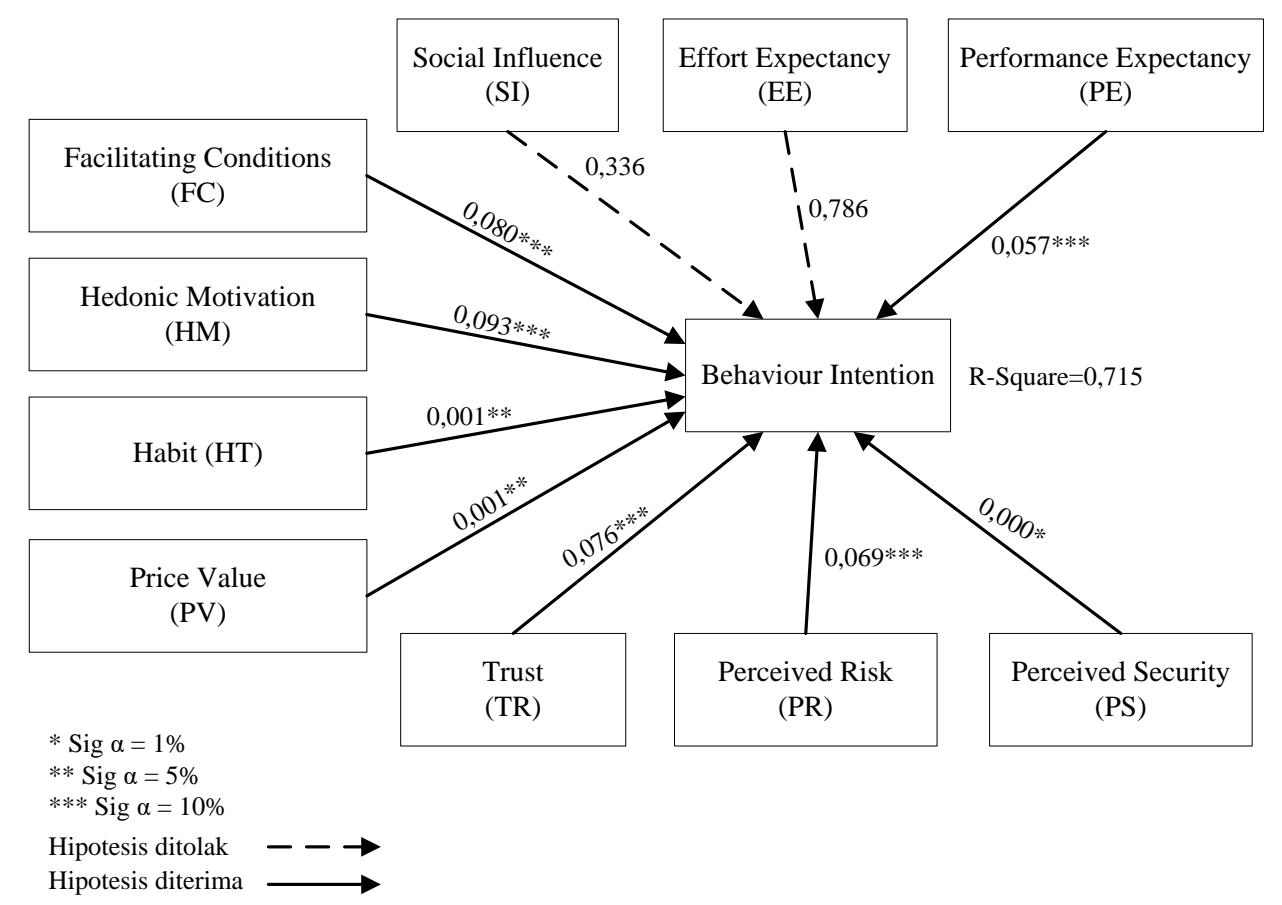

Sumber: Data Primer (diolah), 2020

Gambar 3.

Hasil Analisis Model Penelitian

Berdasarkan Gambar 3 dapat diketahui bahwa terdapat dua variabel yang ditolak yaitu variabel effort expectancy $(\mathrm{H} 2)$ dan social influence $(\mathrm{H} 3)$, karena kedua hipotesis ini memiliki nilai T hitung lebih kecil T tabel dan nilai signifikansi lebih besar dari 5\%. Sementara untuk hipotesis H1, H4, H5, H6, H7, H8, H9, H10 menunjukkan bahwa semuanya terbukti dan dapat diterima.

\section{SIMPULAN DAN SARAN}

Berdasarkan penelitian di atas, maka dapat simpulkan bahwa tingkat penerimaan e-money di kalangan mahasiswa DIY berdasarkan variabel performance expectancy, effort expectancy, social influence, facilitating conditions, habit, motivation hedonic, price value, trust, perceived risk, perceived security, dan behavior intention masuk dalam kategori "Baik". Faktor-faktor yang berpengaruh positif terhadap variabel behavior intention dari yang paling berpengaruh signifikan berdasarkan standardized coefficients, seperti yang ditunjukkan pada keluaran path coefficients adalah Perceived Security, Price Value, Habit, Performance Expectancy, Trust, Facilitating Conditions, dan Hedonic Motivation. Sedangkan Perceived risk merupakan faktor yang berpengaruh negatif terhadap variabel behavior intention. Kemudian terdapat dua faktor yang tidak mempengaruhi behavior intention, yaitu Effort Expectancy dan Social Influence.

Berdasarkan kesimpulan di atas, maka terdapat beberapa rekomendasi atau saran yang bisa peneliti ajukan kepada para penyedia layanan e-money selaku pembuat kebijakan mengenai bagaimana caranya meningkatkan penerimaan e-money. Beberapa rekomendasi yang ditawarkan di antaranya adalah: Berdasarkan faktor perceived security, penyedia layanan harus meningkatkan keamanan $e$ money dari segi keamanan informasi data konsumen dan data transaksi. Berdasarkan faktor price value, penyedia layanan e-money harus bisa lebih kreatif untuk menawarkan kelebihan-kelebihan penggunaan e-money dengan banyak promo atau diskon yang ditawarkan maka konsumen akan 
merasakan manfaat yang diterima dengan menggunakan e-money akan lebih besar daripada beban biaya top-up yang dikeluarkan. Berdasarkan faktor habit, penyedia layanan e-money harus menciptakan kondisi di mana menggunakan e-money untuk bertransaksi menjadi kebiasaan. Berdasarkan faktor performance expectancy, penyedia layanan e-money sebaiknya berupaya lagi untuk memperkuat persepsi pengguna bahwa menggunakan e-money sebagai metode pembayaran nontunai akan membantunya dalam melakukan aktivitas-aktivitas tertentu. Berdasarkan faktor trust, penyedia layanan e-money sebaiknya berupaya untuk meningkatkan kepercayaan pengguna maupun calon pengguna terhadap e-money. Berdasarkan faktor facilitating conditions, penyedia layanan $e$ money sebaiknya meningkatkan sumber daya dan dukungannya terhadap pengguna maupun calon pengguna untuk menggunakan layanan e-money. Berdasarkan faktor perceived risk, penyedia layanan e-money sebaiknya berupaya untuk mengurangi persepsi pengguna maupun calon pengguna terhadap risiko yang akan diterima ketika mereka menggunakan e-money sebagai metode pembayaran non tunai. Berdasarkan faktor hedonic motivation, penyedia layanan e-money sebaiknya melakukan pemasaran yang berfokus pada fitur-fitur baru dan inovatif yang dapat menghasilkan persepsi yang lebih positif terhadap penggunaan e-money.

\section{REFERENSI}

Alalwan, A. A., Dwivedi, Y. K., Rana, N. P., \& Algharabat, R. (2018). Examining factors influencing Jordanian customers' intentions and adoption of internet banking: Extending UTAUT2 with risk. Journal of Retailing and Consumer Services, 40, 125-138.

Alharbi, N., Papadaki, M., \& Dowland, P. (2017). The impact of security and its antecedents in behaviour intention of using e-government services. Behaviour \& Information Technology, 36(6), 620-633.

Bank Indonesia. (2019, Maret 27). Laporan Perekonomian Indonesia Tahun 2018. Retrieved January 11, 2010, from bi.go.id: https://www.bi.go.id/id/publikasi/laporan-tahunan/perekonomian/Pages/LPI_2018.aspx

Bank Indonesia. (2020, Agustus). Statistik Sistem Pembayaran. Retrieved January 10, 2020, from bi.go.id: https://www.bi.go.id/id/statistik/sistem-pembayaran/uang-elektronik/contents/transaksi.aspx

Bhatiasevi, V. (2015). An extended UTAUT model to explain the adoption of mobile banking. Information Development, 32(4), 799-814.

Brown, S. A., \& Venkatesh, V. (2005). Model of Adoption of Technology in Households: A Baseline Model Test and Extension Incorporating Household Life Cycle. MIS Quarterly, 399-426.

Durianto, D., Sugiarto, \& Sitinjak, T. (2001). Strategi Menaklukan Pasar Melalui Riset Ekuitas dan Perilaku Merek. Jakarta: PT Gramedia Pustaka Utama.

Ghozali, I. (2011). Aplikasi analisis multivariate dengan program IBM SPSS 19. Semarang: Universitas Diponegoro.

Hill, T., Smith, N. D., \& Mann, M. F. (1987). Role of efficacy expectations in predicting the decision to use advanced technologies: The case of computers. Journal of Applied Psychology, 2(72), 307-313.

Hsiao, C.-H., \& Tang, K.-Y. (2014). Explaining undergraduates' behavior intention of e-textbook adoption: Empirical assessment of five theoretical models. Library Hi Tech, 32(1), 139-163.

Indah. (2018, January 03). Tantangan Indonesia Menuju Cashless Society. Retrieved January 15, 2020, from Good News From Indonesia: https://www.goodnewsfromindonesia.id/2018/01/03/tantangan-indonesiamenuju-cashless-society

Junadi, \& Sfenrianto. (2015). A model of factors influencing consumer's intention to use e-payment system in Indonesia. Procedia Computer Science, 214-220.

Kurniawan, A. W., \& Puspitaningtyas, Z. (2016). Metode Penelitian Kuantitatif. Yogyakarta: Pandiva Buku .

Otoritas Jasa Keuangan. (2019, July 30). Siaran Pers: OJK Fokus Tingkatkan Literasi dan Inklusi Keuangan Pетиda. Retrieved November 6, 2019, from Otoritas Jasa Keuangan: https://www.ojk.go.id/id/beritadan-kegiatan/siaran-pers/Pages/OJK-Fokus-Tingkatkan-Literasi-dan-Inklusi-Keuangan-Pemuda.aspx

Park, J., Amendah, E., Lee, Y., \& Hyun, H. (2019). M-payment service: Interplay of perceived risk, benefit, and trust in service adoption. Human Factors and Ergonomics In Manufacturing, 29(1), 31-43.

Pedersen, P. M., Suh, Y. I., Ahn, T., \& Lee, J. K. (2015). Effect of Trust and Risk on Purchase Intentions in Online Secondary Ticketing: Sport Consumers and Ticket Reselling. South African Journal for Research in Sport, Physical Education and Recreation, 37(2), 131-142.

Evaluasi Tingkat Penerimaan E-Money Di Kalangan Mahasiswa Yogyakarta Menggunakan Modifikasi Utaut2

Irfan Evan, Dkk 
Rader, N. E., C.May, D., \& Goodrum, S. (2015). An Empirical Assessment Of The "Threat of Victimization: "Considering Fear of Crime, Perceived Risk, Avoidance, and Defensive Behaviors. Sociological Spectrum, 27(5), 475-505.

Sanctis, G. D. (1983). Expectancy Theory as an Explanation of Voluntary Use of a Decision-Support System. Psychological Reports, 52(1), 247-260.

Slade, E. L., Dwivedi, Y. K., Piercy, N. C., \& Williams, M. D. (2015). Modeling Consumers' Adoption Intentions of Remote Mobile Payments in the United Kingdom: Extending UTAUT with Innovativeness, Risk, and Trust. Psychology \& Marketing, 32(8), 860-873.

Sugiyono. (2010). Metode Penelitian Bisnis. Bandung: Alfabeta.

Venkatesh, V., Morris, M. G., Davis, G. B., \& Davis, F. D. (2003). User acceptance of information technology: Toward a unified view. MIS Quarterly: Management Information Systems, 3(27), 425-478.

Venkatesh, V., Thong, J. Y., \& Xu, X. (2012). Consumer Acceptance and Use of Information Technology: Extending the Unified Theory of Acceptance and Use of Technology. MIS Quarterly, 36(1), 157-178.

Yang, Y., Liu, Y., Li, H., \& Yu, B. (2015). Understanding perceived risks in mobile payment acceptance. Industrial Management \& Data Systems, 115(2), 253-269. 